\title{
Aneusomy 17 in Breast Cancer: Its Role in HER-2/neu Protein Expression and Implication for Clinical Assessment of HER-2/neu Status
}

\author{
Sijian Wang, M.D., Ph.D., M. Hossein Saboorian, M.D., Eugene P. Frenkel, M.D., Barbara B. Haley, M.D., \\ Momin T. Siddiqui, M.D., Sefik Gokaslan, M.D., Linda Hynan, Ph.D., Raheela Ashfaq, M.D. \\ Department of Pathology (SW, MHS, MTS, SG, RA), Department of Internal Medicine (EPF, BBH), and \\ Academic Computing Services (LH), The University of Texas Southwestern Medical Center, Dallas, Texas
}

HER-2/neu protein overexpression in breast cancer is mostly caused by HER-2/neu gene amplification. However, it is unclear whether aneusomy 17 may also play a role. Using immunohistochemistry assay (IHC) with DAKO antibody and manual quantitation, 189 specimens were selected from archival invasive breast cancer specimens, including most IHC-positive and some IHC-negative cases $(n=158$ and 31, respectively). They were then analyzed by PathVysion fluorescence in situ hybridization (FISH) assay (Vysis, Inc., Downers Grove, IL) and by an image analyzer (ACIS; ChromaVision Medical Systems, Inc., San Juan Capistrano, CA)-assisted IHC quantitation. Ninety-two cases contained disomy 17 (chromosome 17 centromere, 1.76-2.25 signals per cell) whereas 97 cases had aneusomy 17, including 82 with low polysomy (2.26-3.75 signals per cell), 10 with high polysomy ( $\geq 3.76$ signals per cell), and 5 with hypodisomy ( $\leq 1.75$ signals per cell). HER-2/neu protein expression had the highest correlation with HER-2/neu gene dosage (copy number; $r=.826$ ), followed by the HER-2/neu gene to chromosome 17 ratio $(r=.733)$. The lowest correlation was with the chromosome 17 copy number $(r=.307)$, on which the 10 cases with high polysomy 17 had a disproportionately high impact. The FISH assay using the PathVysion criterion for HER-2/neu gene amplification (HER-2/neu gene to chromosome 17 ratio, $\geq 2.00$ ) achieved higher concordance

Copyright (C) 2002 by The United States and Canadian Academy of Pathology, Inc.

VOL. 15, NO. 2, P. 137, 2002 Printed in the U.S.A.

Date of acceptance: October 30, 2001.

Research funding for statistical consulting was provided in part by the Simmons Cancer Center, The University of Texas Southwestern Medical Center.

None of the authors had any financial or consultant relationship with any of the companies whose products were used in this study. No corporate funding was received for this study.

Address reprint requests to: Raheela Ashfaq, M.D., Department of Pathology, The University of Texas Southwestern Medical Center, 5323 Harry Hines Boulevard, Dallas, TX 75390-9072; e-mail: ashfaq.raheela@pathology.swmed.edu; fax: 214-590-2721. with ACIS IHC than did an alternative FISH criterion (absolute HER-2/neu gene copy number, $\geq 4.00$ signals per cell). Most ACIS IHC-PathVysion FISHdiscordant cases contained disomy or low polysomy 17 , whereas all 10 cases with high polysomy 17 had no such discordance. However, two cases with monosomy 17 had ACIS IHC-PathVysion FISH discordance, i.e., with gene amplification, but no protein overexpression. Both cases would have had no gene amplification if the alternative FISH criterion had been used. In conclusion, aneusomy 17 is common in breast cancer. Except in a certain subset of cases, aneusomy 17 probably is not a significant factor for HER-2/neu protein expression or for clinical assessment of HER-2/neu status.

KEY WORDS: Aneusomy, Breast cancer, erbB-2, Fluorescence in situ hybridization, HER-2/neu, Image analysis, Immunohistochemistry.

Mod Pathol 2002;15(2):137-145

HER-2/neu oncoprotein, also known as erbB-2, is overexpressed in approximately $20-30 \%$ breast cancers (1-3). Laboratory assessment of HER-2/neu status has become a critical step in determining the patient's eligibility for Herceptin treatment.

Located on the long arm of chromosome 17 (17q12-21.32), the HER-2/neu gene encodes a member of the epithelial growth factor receptors on the cytoplasmic membrane (4). HER-2/neu gene expression is primarily regulated by two mechanisms. Transcription activation is responsible for HER-2/neu gene expression in the normal breast tissue $(5,6)$, whereas HER-2/neu gene amplification is found in $>90 \%$ of the breast cancer cases that have HER-2/neu protein overexpression $(1,7,8)$. In fact, this observation forms the basis for a clinical laboratory to evaluate HER-2/neu status in archival breast cancer specimens by using either immunohistochemistry (IHC) for protein expression and/or 
fluorescence in situ hybridization (FISH) for gene amplification.

In practice, however, how to evaluate HER-2/neu status in breast cancer still remains a hotly debated issue. One reason is that IHC and FISH assays have shown a relatively high rate of discordance (9-11). Although HER-2/neu protein overexpression in the presence of the specific gene amplification is presumably through the increased gene dosage, such gene dosage increase may also conceivably occur because of a nonspecific increase in chromosome 17 copy number per cell (polysomy 17). Indeed, a significant number of breast cancer specimens have shown aneusomy 17, i.e., deviation from the normal state of disomy 17 (two copies of chromosome 17 per cell), with either more (polysomy) or fewer (hypodisomy) copies (12-14). Such findings have raised an important question, i.e., what role, if any, the chromosome 17 copy number plays in HER-/neu gene dosage and protein overexpression.

In a recent pilot study, we found that the IHC scores obtained by manual quantitation had the highest correlation with the HER-2/neu gene copies number, followed by with HER-2/neu gene amplification, and lowest, yet still statistically significant, with chromosome 17 copy number (15), suggesting that aneusomy 17 may have some, albeit probably limited, contribution to HER-2/neu protein expression. However, further investigation was hampered by technical limitations of the manual IHC quantitation that produced only crude and intrinsically subjective estimations of highly variable protein staining intensities in individual cells. This technical problem was alleviated considerably by the use of a new image analyzer, the Automated Cellular Imaging System (ACIS, ChromaVision Medical Systems, Inc., San Juan Capistrano, CA), which had resulted in significantly higher concordance and correlation between the IHC and FISH assays (16). In this study, we used ACIS-assisted IHC quantitation and PathVysion (Vysis, Inc., Downers Grove, IL) FISH assays to investigate the role of aneusomy 17 in HER-2/neu protein expression and its implication in clinical assessment of HER-2/neu status.

\section{MATERIALS AND METHODS}

\section{Specimen Procurement and Processing}

The specimens were selected from consecutive mastectomies and breast core biopsies performed at The University of Texas Southwestern Medical Center between August 1998 and March 2000. The specimens were fixed in $10 \%$ neutral buffered formalin and then paraffin embedded as described elsewhere (9). After histologic diagnosis was made, one representative tumor tissue block from each of the infiltrating breast carcinoma specimens was evaluated for the HER-2/neu status.

\section{IHC Assay}

The IHC assay for HER-2/neu protein has been described elsewhere (9). Briefly, the paraffinembedded tissue blocks were cut to $3-\mu \mathrm{m}$ sections that were then deparaffinized and heat treated for antigen retrieval. The antibody, A0485 (DAKO, Carpenteria, CA), was used as the primary anti-HER2/neu antibody in optimal dilution of 1:3500 determined in our laboratory. Biotinylated, streptavidin/ biotin-labeled secondary antibody and related reagents were provided in the Level 2 USA UltraStreptavidin Multi-Species Detection System (Signet Laboratories, Dedham, MA). All IHC assays were performed on an automated TechMate 1000 immunostainer (Ventana Medical Systems, Tucson, AZ).

Upon completion of the IHC staining, all slides were first quantitated using the manual method as described elsewhere (9). The cytoplasmic membrane staining of the invasive cancer component was graded as negative, low $(1+)$, medium $(2+)$, or high positive $(3+; 9)$. Nonspecific background staining was mostly negligible, as was staining of benign ductal and lobular epithelium. Hence, this immunostaining was not subtracted from the score of the invasive component. The cases with IHC $3+$ staining were defined as having HER-2/neu protein overexpression, whereas the cases with IHC negative, $1+$, or $2+$ staining were defined as having no HER-2/neu overexpression.

The ACIS (ChromaVision Medical Systems, Inc., San Juan Capistrano, CA) consists of an automated robotic bright-field microscope module that is linked to a computer through a Microsoft Windows NT-based software interface. The same tissue sections analyzed previously by the manual IHC quantitation were scanned, and the tissue images were converted to digital files. The system was calibrated with control slides that had negative, low-positive, and high-positive staining of HER-2/neu protein. According to the manufacturer, the ACIS system is able to distinguish cell membrane staining from cytoplasmic staining, using so-called color-space transformation, proprietary technology. ACIS then specifically quantitates the cytoplasmic membrane staining on an essentially continuous 256-level scale. The manufacturer recommends selection of five areas with highest staining intensity for quantitation. In this study, 10 highest-stained areas of invasive cancer component were quantitated to reduce potential sampling variations. As the manufacturer recommends, the cases with an average score of $\geq 2.0$ were defined as having HER-2/neu protein overexpression, whereas the cases with average score of $<2.0$ were defined as having no over- 
expression. The cases with the ACIS scores between 1.8 and 2.2 were subjected to a repeat quantitation, and average of the two scores was used as the final score.

\section{FISH Assay}

A FISH assay, PathVysion, was used to evaluate the genetic variables, including HER-2/neu gene and chromosome 17 copy number, as previously described (9). Briefly, the PathVysion assay was performed using the manufacturer's recommended protocol on $4-\mu \mathrm{m}$ sections prepared from paraffinembedded tissue blocks. Two directly labeled probes, LSI HER-2/neu SpectrumOrange and CEP 17 SpectrumGreen, were used to detect the distinct fluorescent signals in individual cells for the respective HER-2/neu gene and alpha satellite sequence of chromosome 17 centromere (for enumeration of chromosome 17). In each breast cancer specimen, $\geq 60$ cells in the invasive component were evaluated. The manufacturer-provided cell lines with and without HER-2/neu gene amplification were used as controls. The FISH-defined genetic variables were reported as follows: HER-2/neu gene copy number (signals per cell), average chromosome 17 copy number (signals per cell), and the average HER-2/neu gene to chromosome 17 signal ratio. As the manufacturer recommended, the specimens with HER-2/neu gene to chromosome 17 ratio of $\geq 2.00$ were designated as having HER-2/ neu gene amplification, and the ones with ratio of $<2.00$, as having no gene amplification.

The definition of aneusomy 17 was mainly intended for the convenience of the data analysis and discussion. Specimens with a chromosome 17 copy number in the range of 1.76-2.25 signals per cell were defined as having disomy 17 . Such range took into account that even a given tumor specimen with predominantly disomy 17 could still show some deviation from average of 2 signals per cell, because of tumor's genetic instability, high mitotic index, and potential nuclear truncation through tissue sectioning. The other cases were considered to have aneusomy 17: either hypodisomy ( $\leq 1.75$ signals per cell) or polysomy ( $\geq 2.26$ signals per cell). The cases with polysomy 17 were further divided into $0.5 \mathrm{signal} / \mathrm{cell}$ intervals.

\section{Data Analyses}

Statistical analyses were conducted using the ACIS scores for HER-2/neu protein expression and FISH scores for the corresponding genetic variables, i.e., chromosome 17, HER-2/neu gene copy number, and HER-2/neu gene to chromosome 17 ratio. Pearson product-moment correlations were employed to examine the relationship between pairs of variables. Pairwise tests of Pearson product-moment correlations for dependent correlations (17) were conducted to examine the equivalence of each of these associations. A partitioning technique, K-means clustering (18), was used to conduct cluster analysis for subsets of cases with different chromosome 17 copy numbers.

\section{RESULTS}

\section{Case Selection}

In the first screening step, the IHC assay with manual quantitation was used for all infiltrating breast cancer specimens that were consecutively accessioned between August 1998 and March 2000.

On the basis of the manual IHC scores, the PathVysion FISH assay was performed on 199 cases that consisted of two subgroups with 48 and 151 cases, respectively. The first 48 specimens (accessioned between August 1998 and February 1999) were selected after the cases had been stratified by the manual IHC scores (negative, $1+, 2+$, or $3+$ ), therefore representing equal sampling of each IHC subset. The other 151 specimens (accessioned between March 1999 and March 2000) contained all cases with positive IHC staining $(1+$ to $3+$, total 136 cases) and only 15 random cases with negative IHC staining. The exclusion of most cases with negative IHC staining was based on the previous finding that none of such cases had HER-2/neu gene amplification (9). This selection process resulted in underrepresentation of the IHC-negative specimens for the FISH assay. Nonetheless, analyses of the IHC negative cases revealed no HER-2/neu gene amplification and no significant aneusomy 17 . The underrepresentation of the IHC-negative specimens did not appear to have significant impact on the data analyses or the conclusions (16).

ACIS was then used to quantitate the IHC staining in 189 of these 199 FISH-analyzed cases, including 158 manual IHC-positive cases and 31 manual IHC-negative cases, using the same IHC slides originally analyzed by the manual quantitation. The ACIS quantitation was not performed on the remaining 10 cases because of unavailability of the original slides.

\section{Case Distribution}

Figure 1 illustrates the distribution pattern of chromosome 17 copy numbers in these 189 cases. Ninety-two cases (48.7\% of total) had disomy 17 (1.76-2.25 signals per cell), whereas the remaining 97 cases (51.3\% of total) had aneusomy 17 . Most of these 97 cases had relatively low polysomy 17 (2.26-3.75 signals per cell). Only 10 cases $(5.3 \%$ of total) had high polysomy 17 ( $\geq 3.76$ signals per cell). 


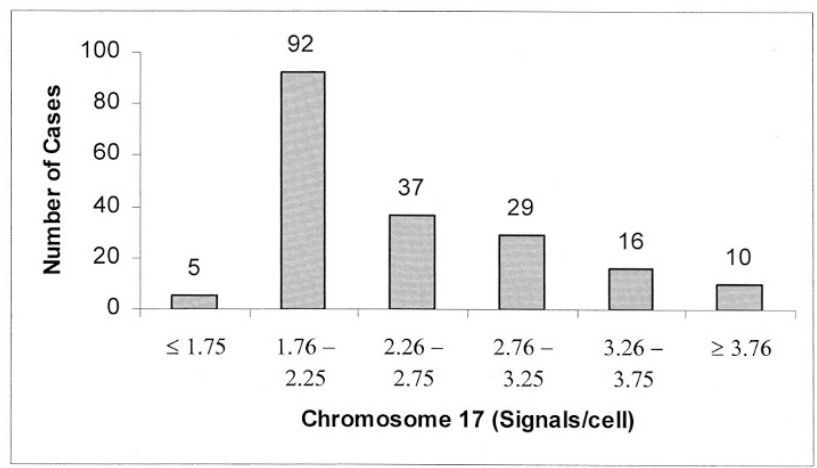

FIGURE 1. Distribution pattern of chromosome 17 copy number. The 189 cases are arranged in subsets, according to the chromosome 17 copy number (signals per cell).

On the other end of the spectrum, only 5 cases ( $2.6 \%$ of total) had hypodisomy ( $\leq 1.75$ signals per cell).
Then, the distribution pattern of the chromosome 17 copy number was contrasted with that of the HER-2/neu gene copy number (Fig. 2). Overall, the distribution of the chromosome 17 copy number was in a much narrower range when compared with that of the HER-2/neu gene copy number (Fig. $2 \mathrm{~A})$. These cases were further stratified based on the HER-2/neu protein expression (Fig. 2B-C). Most of the cases without HER-2/neu protein overexpression (ACIS score of $<2.0$ ) clustered in a small area, with both chromosome 17 and HER-2/neu gene copy numbers in a very narrow range (Fig. $2 \mathrm{~B}$ ). In contrast, the cases with HER-2/neu protein overexpression (ACIS score of $\geq 2.0$ ) demonstrated much wider distribution of HER-2/neu gene copy number, yet still maintained a relatively narrow range of chromosome 17 copy number (Fig. 2C). As a result, many of these cases with HER-2/neu protein overexpression had relatively high HER-2/neu gene am-
A
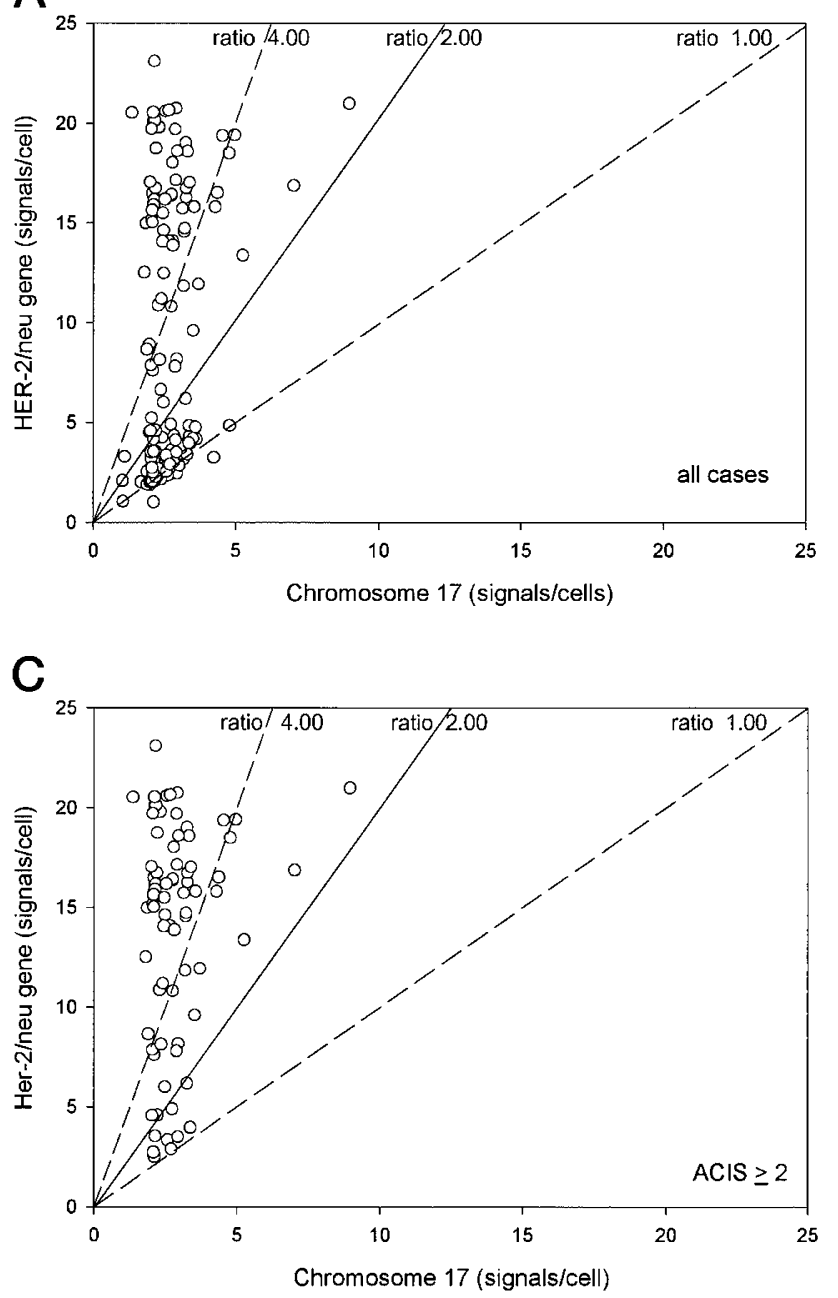

B

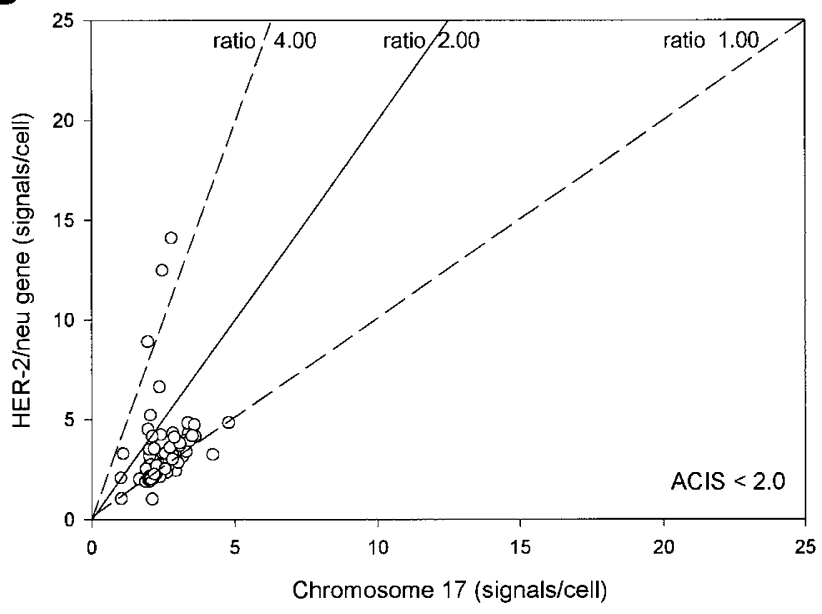

FIGURE 2. Comparison of distribution patterns of chromosome 17 copy number and HER-2/neu gene copy number. The cases (open circles) are plotted based on the respective chromosome 17 copy number (signals per cell) and HER-2/neu gene copy number (signals per cell). Both variables are drawn in the same scale. Solid line represents the PathVysion cutoff for gene amplification (HER-2/neu gene to chromosome 17 ratio, 2.00). The other two lines represent the respective HER-2/neu gene to chromosome 17 ratios of 1.00 (dashed line) and 4.00 (dashed line). A, all 189 cases. B, the cases with no HER-2/neu protein expression (Automated Cellular Imaging System immunohistochemistry scores of $<2.0$ ). C, the cases with HER$2 /$ neu protein expression (ACIS scores of $\geq 2.0$ ). 
plification (HER-2/neu gene to chromosome 17 ratio, $\geq 4.00$, represented by dashed line in Fig. 2C).

\section{Relationship between HER-2/neu Protein Expression and the Genetic Variables}

In the second part of this study, the relationship between HER-2/neu protein expression and the genetic variables is analyzed (Fig. 3). Statistical analysis (Pearson product-moment correlation) revealed that correlation between HER-2/neu protein expression and each of the three FISH-defined genetic variables was statistically significant. However, the correlation between the HER-2/neu protein expression and chromosome 17 was lowest, with $r=.307$ ( $P<.0001$; Fig. 2A). On the contrary, HER-2/neu protein expression had much higher correlation with either of the other two genetic variables, with the respective $r=.733(P<.0001)$ for the HER-2/neu gene to chromosome 17 ratio (Fig. 3B) and even higher $r=.826(P<.0001)$ for the HER-2/neu gene copy number (Fig. 3C). In addition, the difference between any two of these three correlations was statistically significant $(P<.0001)$.

As noted above (Fig. 1), there were 10 cases with relatively high polysomy 17 ( $\geq 3.76$ signals per cell; filled circles in Fig. 3). Statistical cluster analysis revealed that these 10 cases were in a cluster, distinct from other 179 cases. Impact of these 10 cases on the overall correlation between HER-2/neu protein expression and the genetic variables was analyzed. If the 10 cases were excluded, the already low correlation between HER-2/neu protein expression and chromosome $17(r=.307)$ would be even lower, with $r=.243(P<.001)$. On the other hand, the exclusion of these 10 cases had very limited effect on the correlations between HER-2/neu pro-
A

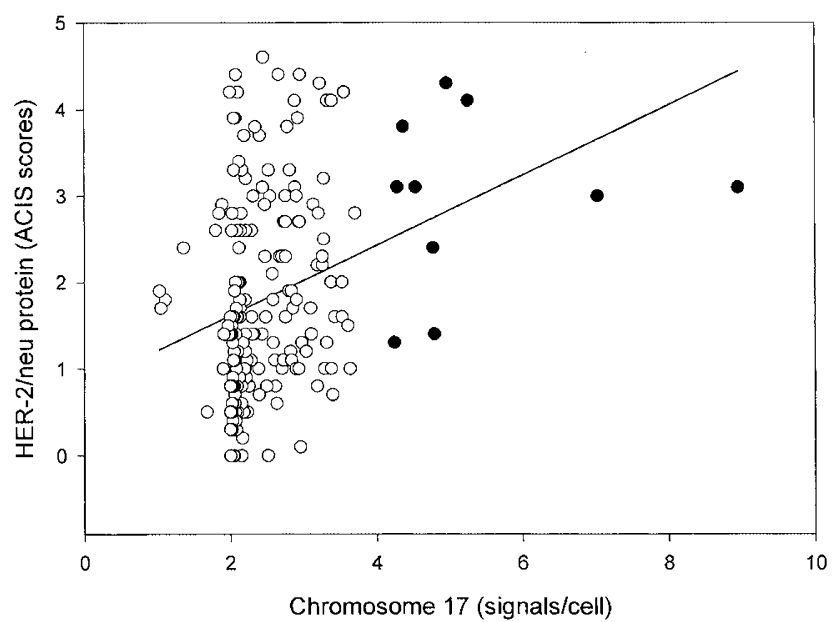

C

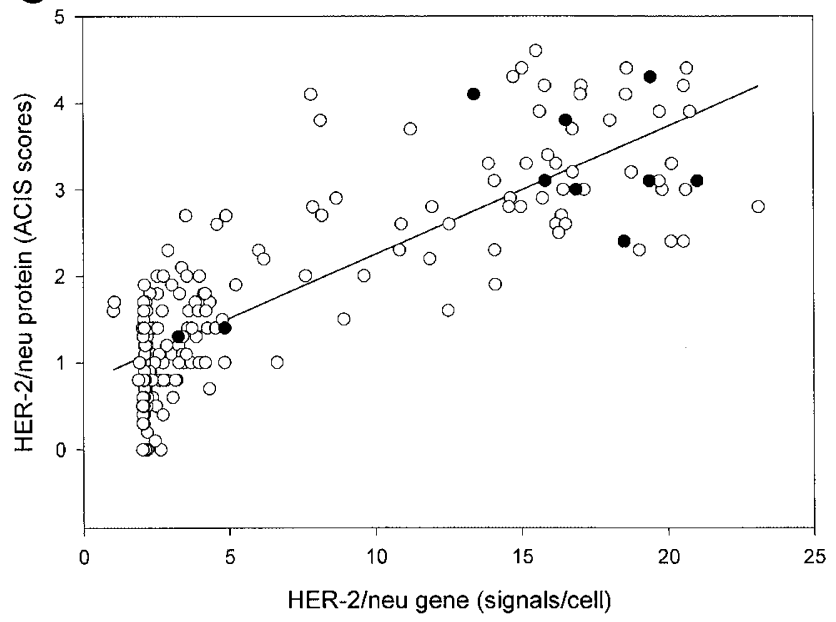

B

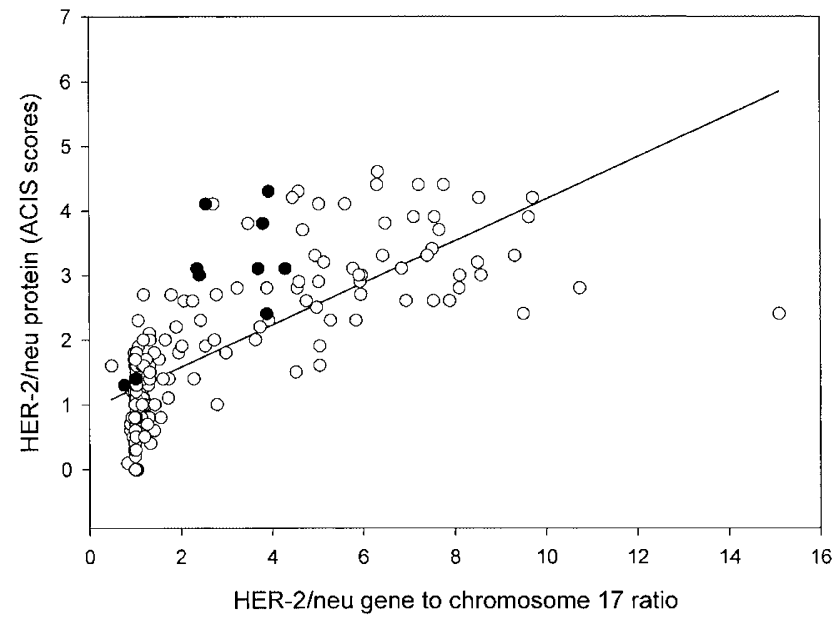

FIGURE 3. Correlation between HER-2/neu protein expression and the genetic variables. The 189 cases are depicted based on HER-2/neu protein expression (Automated Cellular Imaging System immunohistochemistry scores) and each of the three genetic variables. The 10 cases with high polysomy 17 ( $\geq 3.76$ signals per cell) are shown in closed circles, whereas all other 179 cases are shown in open circles. A, genetic variable: chromosome 17 copy number (signals per cell). B, genetic variable: HER-2/neu gene to chromosome 17 ratio. C, genetic variable: HER-2/neu gene copy number (signals per cell). 
tein expression and either HER-2/neu gene copy number or HER-2/neu gene to chromosome 17 ratio, with the respective $r=.819(P<.0001$; original, $.826)$ and $r=.757(P<.0001$; original, .733).

\section{Impact of Aneusomy 17 on Clinical Assessment} of HER-2/neu Status

The main concern for aneusomy 17 in a clinical laboratory is whether it could be a factor for discordance between IHC and FISH assays. To address this question, we focused primarily on the individual cases that had discordance between ACIS IHC and PathVysion FISH assays. In such cases, increased HER-2/neu gene dosage conceivably may be a result of polysomy 17, without specific HER$2 /$ neu gene amplification. If this scenario were true, there could have been discordance between two different FISH criteria, i.e., with no gene amplification by PathVysion criterion (HER-2/neu gene to chromosome 17 ratio of $\geq 2.00$ ), but with gene amplification by an alternative criterion (absolute HER-2/neu gene copy number of $\geq 4.00$ signals per cell)

Seventeen of the 189 cases had discordance between ACIS IHC and PathVysion results (Table 1). Analysis was conducted according to chromosome 17 copy number, i.e., disomy and low polysomy; high polysomy; and hypodisomy.

Fifteen of these 17 discordant cases had either disomy 17 or low polysomy 17 Interestingly, 14 of these 15 cases also had concordance between the two FISH criteria for gene amplification, i.e., seven cases with a ratio of $<2.00$ and HER-2/neu gene copy number of $<4.00$ signals per cell and seven cases with a ratio of $\geq 2.00$ and absolute HER-2/neu gene copy number of $\geq 4.00$ signals per cell. Moreover, these discordant cases had mostly borderline ACIS scores (approximately 2.0, data not shown).

The cases with hypodisomy 17 revealed some interesting findings. Among the five cases, three cases had complete concordance between ACIS IHC and PathVysion FISH assays, as well as between two FISH criteria. However, the remaining two cases had discordance between ACIS and PathVysion, as well as discordance between two FISH criteria. The two cases actually had monosomy 17 (1.11 and 1.03 signals per cell) and no HER-2/neu protein overexpression (ACIS scores, 1.8 and 1.9). They had apparent HER-2/neu gene amplification by PathVysion criterion (ratio, 2.98 and 2.02), but no such amplification by the alternative criterion (HER-2/neu gene copy number, 3.29 and 2.08 signals per cell). One case is shown in Figure 4A.

All 10 cases with high polysomy showed concordance between ACIS IHC and PathVysion FISH assay, including 2 cases without HER-2/neu gene amplification and 8 cases with gene amplification (PathVysion criterion). Figure 4B shows one of the cases. Nine of 10 cases also had concordance between the two FISH criteria.

Furthermore, the alternative FISH criterion was compared with the PathVysion criterion for discordance between IHC and FISH assays. There were 12 of 189 cases with discordance between two FISH criteria, including 10 cases with an HER-2/neu gene to chromosome 17 ratio of $<2.00$, but an HER-2/ neu gene copy number of $\geq 4.00$ signals per cell, and the other 2 cases with a ratio of $\geq 2.00$ but a HER-2/neu gene copy number of $<4.00$ signals per cell (Table 1). Nine of these 12 cases had discordance between ACIS and alternative FISH criterion. There were total of 23 cases with such FISH-FISH discordance, including 14 ACIS-PathVysion discordant cases with disomy or low polysomy.

\section{DISCUSSION}

In this study, we investigated the role of aneusomy 17 in HER-2/neu protein expression, with a particular interest in its implication for clinical in-

TABLE 1. Cases with Discordance between ACIS IHC and PathVysion FISH Assays

\begin{tabular}{|c|c|c|c|c|c|}
\hline \multirow{4}{*}{$\begin{array}{l}\text { Chromosome } 17 \\
\text { Signals per Cell }\end{array}$} & \multicolumn{4}{|c|}{ HER-2/ neu Gene to Chromosome 17 Ratio } & \multirow{4}{*}{ Subtotal } \\
\hline & \multicolumn{2}{|c|}{$<2.00$} & \multicolumn{2}{|c|}{$\geq 2.00$} & \\
\hline & \multicolumn{2}{|c|}{ HER-2/neu Gene } & \multicolumn{2}{|c|}{ HER-2/Neu Gene } & \\
\hline & $\begin{array}{c}<4.00 \text { Signals } \\
\text { per Cell }\end{array}$ & $\begin{array}{l}\geq 4.00 \text { Signals } \\
\text { per Cell }\end{array}$ & $\begin{array}{c}<4.00 \text { Signals } \\
\text { per Cell }\end{array}$ & $\begin{array}{c}\geq 4.00 \text { Signals } \\
\text { per Cell }\end{array}$ & \\
\hline$\leq 1.75$ & $0(2)$ & $0(0)$ & $2(2)$ & $0(1)$ & $2(5)$ \\
\hline $1.76-2.25$ & $3(67)$ & $0(0)$ & $0(0)$ & $4(25)$ & $7(92)$ \\
\hline $2.26-2.75$ & $2(18)$ & $1(2)$ & $0(0)$ & $2(17)$ & $5(37)$ \\
\hline $2.76-3.25$ & $1(12)$ & $0(2)$ & $0(0)$ & $1(15)$ & $2(29)$ \\
\hline $3.26-3.75$ & $1(4)$ & $0(5)$ & $0(0)$ & $0(7)$ & $1(16)$ \\
\hline$\geq 3.76$ & $0(1)$ & $0(1)$ & $0(0)$ & $0(8)$ & $0(10)$ \\
\hline Subtotal & 7 (104) & $1(10)$ & $2(2)$ & $7(73)$ & 17 (189) \\
\hline
\end{tabular}

The numbers without parentheses represent cases with discordance between ACIS IHC and PathVysion FISH assays, including ones without HER-2/neu gene amplification (ratio of $<2.00$ ) but with HER-2/neu protein overexpression (ACIS scores of $\geq 2.0$ ); and ones with HER-2/neu gene amplification (ratio of $\geq 2.00$ ) but without HER-2/ neu protein overexpression (ACIS scores of $<2.0$ ). The numbers in parentheses represent total number of cases in each subset. 
A

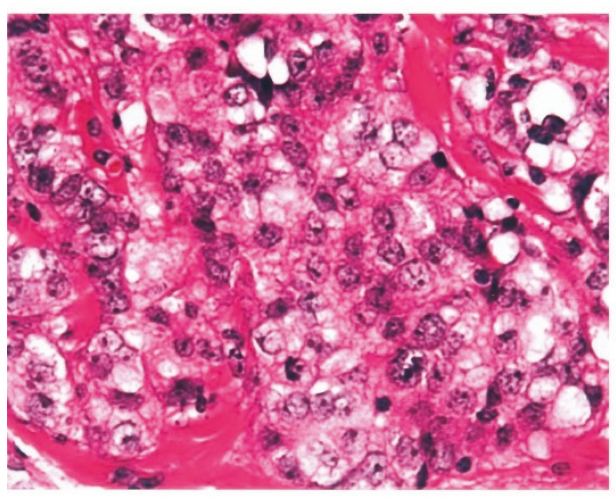

Monosomy

$\mathrm{H} \& \mathrm{E}(40 \mathrm{x})$

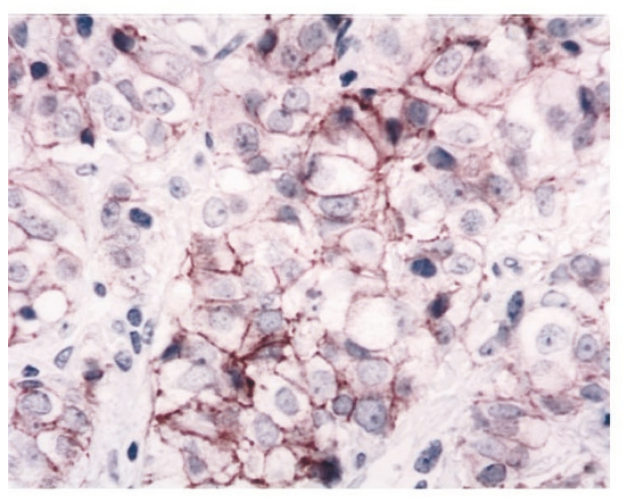

Monosomy

IHC Her 2/neu (40x)

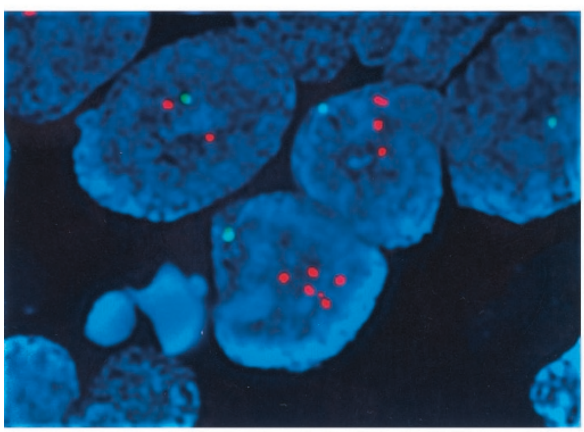

Monosomy

FISH Her 2/neu (100x)
B

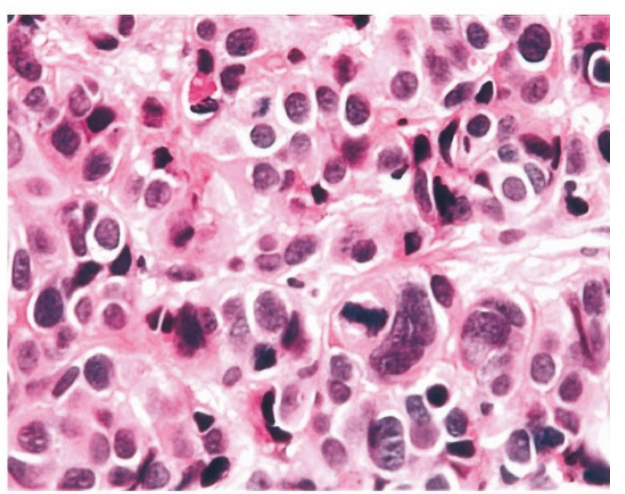

Polysomy

H \& E (40x)

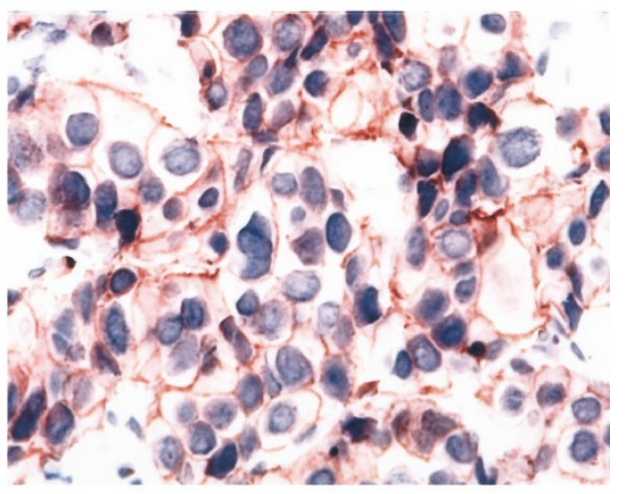

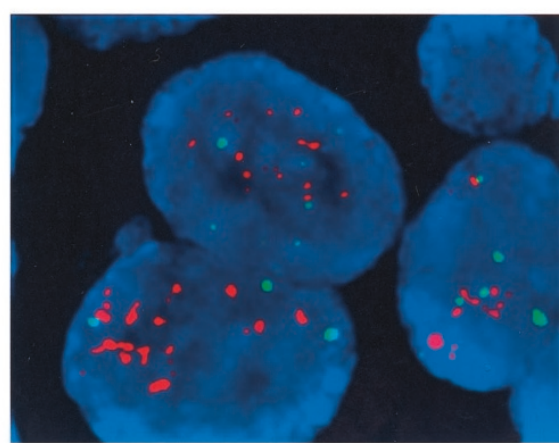

Polysomy

FISH Her 2/neu (100x)

FIGURE 4. The immunohistochemistry (IHC) and fluorescence in situ hybridization (FISH) results in two representative cases. Two representative cases are shown for the IHC staining and PathVysion FISH assay orange signals are for HER-2/neu gene, and the green signals are for chromosome 17 centromere). A, one case that had monosomy 17 (chromosome 17 copy number, 1.11 signals per cell) and HER-2/neu gene amplification by PathVysion criterion (HER-2/neu gene to chromosome 17 ratio, 2.98), but no HER-2/neu protein overexpression ACIS IHC score, 1.8). It had no HER-2/neu gene amplification by the alternative FISH criterion (HER-2/neugene copy number, 3.26 signals per cell). B, one case had high polysomy 17 (chromosome 17 copy number, 7.02 signals per cell), HER-2/neu gene amplification by PathVysion criterion (HER-2/neu gene to chromosome 17 ratio, 2.40), and HER-2/neu protein overexpression (ACIS score, 3.0). It also had concurrent HER-2/neu gene amplification by the alternative FISH criterion (HER-2/neu gene copy number, 16.87 signals per cell). Because of the threedimensional nature of the cells, not all signals are present in the plane of this particular figure. 
terpretation of IHC and FISH assay result. Although the relationship between HER-2/neu protein expression and HER-2/neu gene copy number was previously analyzed in breast cancer cell lines (19), this study was the first to address the issue at the level of individual cells in a large cohort of archival invasive breast cancer specimens.

Aneusomy 17 was very common in this cohort, present in $>50 \%$ of 189 cases. However, the distribution pattern of chromosome 17 was distinct from that of HER-2/neu gene copy number. After the cases had been stratified by HER-2/neu protein overexpression, the former was still in the same range for the two subsets (ACIS scores of $\geq 2.0$ and $>2.0$ ), but the latter showed little overlap between the two subsets. These findings strongly suggest that in most specimens, aneusomy 17 alone is probably not a significant contributor to HER-2/ neu gene copy number.

The correlations between HER-2/neu protein expression and each of the three genetic variables, i.e., chromosome 17 copy number, HER-2/neu gene copy number, and HER-2/neu gene to chromosome 17 ratio, were all statistically significant, with the one with HER-2/neu gene being the highest and the one with chromosome 17, lowest. Although similar observation was made in the previous pilot study (15), this study was facilitated by the use of essentially continuous ACIS IHC scores (16). These findings support the hypothesis that HER-2/neu protein expression is highly related to the corresponding HER-2/neu gene dosage, which in turn reflects the net effects of chromosome 17 copy number and HER-2/neu gene amplification. Such gene dosage effect has also been found in some human disorders, such Charcot-Marie-Tooth polyneuropathy (20). It should be emphasized that although all correlations were statistically significant, there were still considerable variations in HER-2/ neu protein expression for any given level of each genetic variable, suggesting that other factors, such as transcription regulation, tumor cell heterogeneity, or assay variability, may be important. This study also adds another line of supporting evidence for the validity of ACIS quantitation of IHC staining.

Our analysis also revealed that the 10 cases with high polysomy 17 (chromosome 17 copy number $\geq 3.76$ signals per cell) were statistically distinct from the other 179 cases. When these 10 cases were excluded, the already low correlation between HER2/neu protein expression and chromosome 17 copy number became even lower. This finding suggests that the cases with high polysomy 17 may have disproportionately greater impact on the correlation between HER-2/neu protein expression and chromosome 17 copy number. In other cases, effect of chromosome 17 copy number on HER-2/neu protein expression may be very limited, if not negligible.

In a clinical laboratory, the major interest in aneusomy 17 stems from the concern for its potential impact on classification of HER-2/neu status. This issue is particularly true for those cases with the manual IHC $2+$ scores, which often have the highest rate of discordance between IHC and FISH assays (16). In this study, most of the discordant cases had disomy 17 or low polysomy 17, but not high polysomy. Moreover, if aneusomy 17 were significant in discordance, the absolute HER-2/neu gene copy number would have been a better FISH criterion than the HER-2/neu gene to chromosome 17 ratio, because the latter had the tendency to underestimate impact of aneusomy 17. In this cohort, however, the result was opposite. ACIS IHC had lower discordance with PathVysion (17 discordant cases) than with the alternative FISH criterion (23 discordant cases).

Our study indicates that in the absence of HER$2 /$ neu gene amplification, even high polysomy 17 is insufficient to cause significant increase in gene dosage and subsequent HER-2/neu protein overexpression. On the other hand, cases with high polysomy 17, all of which contained concurrent modest HER-2/neu gene amplification (ratio, 2.00-4.00), may have an additive effect on gene dosage and protein expression.

However, aneusomy 17 may play a more critical role in certain cases with monosomy 17 , especially the ones with monosomy 17 and HER-2/neu gene amplification by PathVysion criterion. Such a finding would be readily understandable if the gene dosage is the presumed mechanism for HER-2/neu protein expression. Because of the rarity of such cases (approximately $1 \%$ of total in this study), no statistical analysis was performed. However, we recommend that precautions be taken in such cases. The absolute HER-2/neu gene copy number may need to be considered because the HER-2/neu gene to chromosome 17 ratio alone may not be a reliable indicator for HER-2/neu status.

The above lines of evidence support that compared with the absolute HER-2/neu gene copy number, the PathVysion criterion for HER-2/neu gene amplification with incorporation of the control probe for chromosome 17, in general, is the better approach for a HER2-/neu FISH assay. It should be noted that although the cutoff level of absolute HER-2/neu gene of $\geq 4.00$ signals per cell was used by some FISH assays, such as the INFORM (Ventana Medical Systems), no definite conclusion should be drawn from this study with regard to other particular FISH assays, because the probes in PathVysion and other FISH assays may have different properties. 
In summary, this study found that aneusomy 17 was common in invasive breast cancer specimens, but mainly in the form of low polysomy 17. HER$2 /$ neu protein expression had the highest correlation with HER-2/neu gene dosage and the lowest correlation with aneusomy 17. For clinical assessment of HER-2/neu status, aneusomy 17 was not a significant factor for IHC-FISH discordance in most cases.

Acknowledgments: We thank Fran Saliger, C.T. (A.S.C.P.), Dana Wanzer, C.T. (A.S.C.P.), and Shala Thomas, C.T. (A.S.C.P.), OncoDiagnostic Laboratory, Parkland Memorial Hospital, Dallas, Texas, for the technical assistance.

\section{REFERENCES}

1. Slamon DJ, Clark GM, Wong SG, et al. Human breast cancer: correlation of relapse and survival with amplification of the HER-2/neu oncogene. Science 1987;235:177-81.

2. Slamon DJ, Godolphin W, Jones LA, et al. Studies of the Her/neu proto-oncogene in human breast and ovarian cancer. Science 1989;244:707-12.

3. Revillion F, Bonneterre J, Peyrat JP. ERBB2 oncogene in human breast cancer and its clinical significance. Eur J Cancer 1998;34:791-808.

4. Popescu NC, King CR, Kraus MH. Localization of the human erbB-2 gene on normal and rearranged chromosomes 17 to bands q12-21.32. Genomics 1989;4:362-6.

5. Alroy I, Yarden Y. The ErbB signaling network in embryogenesis and oncogenesis: signal diversification through combinatorial ligand-receptor interactions. FEBS Lett 1997;410:83-6.

6. Reese D, Slamon DJ. HER-2/neu signal transduction in human breast and ovarian cancer. Stem Cell 1997;15:1-8.

7. Naber SP, Tsutsumi Y, Yin S, et al. Strategies for the analysis of oncogene overexpression. Studies of the neu oncogene in breast carcinoma. Am J Clin Pathol 1990;94:125-36.

8. Kallioniemi O-P, Kallioniemi A, Kurisu W, et al. ERBB2 amplification in breast cancer analyzed by fluorescence in situ hybridization. Proc Natl Acad Sci U S A 1992;89:5321-5.
9. Wang S, Saboorian MH, Frenkel E, et al. Laboratory assessment of the status of Her-2/neu protein and oncogene in breast cancer specimens: comparison of immunohistochemistry assay with fluorescence in situ hybridisation assays. J Clin Pathol 2000;53:374-81.

10. Hoang MP, Sahin AA, Ordonez NG, et al. HER-2/neu gene amplification compared with HER-2/neu protein overexpression and interobserver reproducibility in invasive breast carcinoma. Am J Clin Pathol 2000;113:852-9.

11. Ridolfi RL, Jamehdor MR, Arber JM. HER-2/neu testing in breast carcinoma: a combined immunohistochemical fluorescence in situ hybridization approach. Mod Pathol 2000; 13:866-73.

12. Botti C, Pescatore B, Mottolese M, et al. Incidence of chromosome 1 and 17 aneusomy in breast cancer and adjacent tissue: an interphase cytogenetic study. J Am Coll Surg 2000; 190:530-9.

13. Sauer T, Beraki K, Jebsen PW, et al. Numerical aberrations of chromosome 17 in interphase cell nuclei of breast carcinoma cells: lack of correlation with abnormal expression of p53, neu and nm23 protein. APMIS 1998;106:921-7.

14. Ferabegoli F, Ceccarelli C, Santini D, et al. C-erbB-2 overexpression in amplified and non-amplified breast carcinoma samples. Int J Cancer 1999;84:273-7.

15. Wang S, Saboorian MH, Frenkel E, et al. Relative contributions to Her2 protein levels by chromosome 17 aneuploidy and Her2 gene amplification in breast cancer [abstract]. Mod Pathol 2001;14:40A.

16. Wang S, Saboorian MH, Frenkel E, et al. Assessment of HER-2/neu status in breast cancer: Automated Cellular Imaging System (ACIS)-assisted quantitation of immunohistochemical assay (IHC) improves its correlation with fluorescence in situ hybridization assay (FISH). Am J Clin Pathol (in press).

17. Cohen J, Cohen P. Applied multiple regression/correlation analysis for the behavioral sciences. 2nd ed. Hillsdale, NJ: Erlbaum; 1983.

18. Dillon WR, Goldstein M. Multivariate analysis: methods and applications. New York: Wiley; 1984. p. 186-91.

19. Szollosi J, Balazs M, Feuerstein BG, et al. ERBB-2 (HER2/ neu) gene copy number, p185 ${ }^{\mathrm{HER}-2}$ overexpression, and intratumor heterogeneity in human breast cancer. Cancer Res 1995;55:5400-7.

20. Lupski JR. Charcot-Marie-Tooth polyneuropathy. Duplication, gene dosage, and genetic heterogeneity. Pediatr Res 1999;45:159-65. 